\title{
Comparison of UV-VIS and FDOM sensors for in situ monitoring of stream DOC concentrations
}

\author{
E.-J. Lee ${ }^{1}$, G.-Y. Yoo ${ }^{1}$, Y. Jeong ${ }^{1}$, K.-U. Kim ${ }^{1}$, J.-H. Park ${ }^{2}$, and N.-H. Oh ${ }^{1}$ \\ ${ }^{1}$ Graduate School of Environmental Studies, Seoul National University, Seoul 151-742, South Korea \\ ${ }^{2}$ Department of Environmental Science and Engineering, Ewha Womans University, Seoul 120-750, South Korea \\ Correspondence to: N.-H. Oh (ultisol@gmail.com)
}

Received: 6 November 2014 - Published in Biogeosciences Discuss.: 9 December 2014

Revised: 14 April 2015 - Accepted: 30 April 2015 - Published: 28 May 2015

\begin{abstract}
Optical measurements using ultraviolet-visible (UV-VIS) spectrophotometric sensors and fluorescent dissolved organic matter (FDOM) sensors have recently been used as proxies of dissolved organic carbon (DOC) concentrations in streams and rivers at a high temporal resolution. Despite the merits of the sensors, temperature changes and particulate matter in water can interfere with the sensor readings, over- or underestimating DOC concentrations. However, little efforts have been made to compare responses of the two types of the sensors to critical interferences such as temperature and turbidity. The performance of a UV-VIS sensor and an FDOM sensor was compared in both laboratory experiments and in situ monitoring in a forest stream in Korea during three storm events. Although the UV-VIS sensor did not require temperature correction in laboratory experiments using the forest stream water, the deviations of its values from the DOC concentrations measured with a TOC analyzer increased linearly as turbidity increased. In contrast, the FDOM sensor outputs decreased significantly as temperature or turbidity increased, requiring temperature and turbidity correction for in situ monitoring of DOC concentrations. The results suggest that temperature correction is relatively straightforward but turbidity correction may not be simple because the attenuation of light by particles can significantly reduce the sensitivity of the sensors in highly turbid waters. Shifts in composition of fluorophores also need to be carefully tracked using periodically collected samples since light absorbance and fluorescence can vary as the concentrations of dominant fluorophores change.
\end{abstract}

\section{Introduction}

Dissolved organic carbon (DOC), which is a dominant form of organic carbon in many streams and rivers, plays significant roles in aquatic systems. Riverine DOC is the energy source for heterotrophs (Raymond and Bauer, 2000), protects living organisms from UV light (Morris et al., 1995), and affects metal availability (Di Toro et al., 2001). High riverine DOC concentration ([DOC]) can also lower the quality of drinking water by increasing trihalomethane formation potential during water treatment (Hur et al., 2014; Xie, 2004). Thus, many studies on [DOC] have been conducted on a variety of spatial scales, such as streams draining from small watersheds to major rivers from large basins (Aitkenhead and McDowell, 2000; Jeong et al., 2012; Oh et al., 2013).

Studies on DOC release from forest ecosystems showed a close relationship between carbon export and hydrology, indicating an important role of discharge in DOC loads (Jeong et al., 2012; Pellerin et al., 2012; Raymond and Saiers, 2010). Stream DOC load increased as water discharge increased, and thus it was observed that DOC released during storm events accounted for a substantial amount of total carbon export from an ecosystem (Hinton et al., 1997; Raymond and Saiers, 2010; Yoon and Raymond, 2012). Considering that a large variation in water discharge during heavy rainfall can result in large variations in daily as well as annual DOC loads, monitoring stream carbon concentrations with a high temporal resolution during storm events is necessary (Jollymore et al., 2012). This is valid especially in Asian monsoon regions, including South Korea (Kim et al., 2013), where more than $50 \%$ of annual precipitation (an average of $1320 \mathrm{~mm}$ from 1981 to 2010) is concentrated during summer months (Korea Meteorological Administra- 
tion, www.kma.go.kr). Measurements of stream [DOC] with a low temporal resolution (e.g., weekly or monthly) cannot fully capture DOC changes that typically last for just a few hours in small streams during a storm event, resulting in large uncertainty when estimating DOC loads (Jollymore et al., 2012). Thus, optical sensors have been used to achieve high-resolution in situ monitoring of [DOC] (Etheridge et al., 2014; Jollymore et al., 2012; Koehler et al., 2009; Pellerin et al., 2012; Strohmeier et al., 2013).

Two types of optical sensors have been used frequently for this purpose; the ultraviolet-visible (UV-VIS) spectrophotometer (Etheridge et al., 2014; Jeong et al., 2012; Jollymore et al., 2012; Strohmeier et al., 2013) and the fluorescent dissolved organic matter (FDOM) sensor (Pellerin et al., 2012; Saraceno et al., 2009; Watras et al., 2011). UV-VIS sensors use the range of ultraviolet and visible light wavelengths (e.g., 220 to $720 \mathrm{~nm}$ ) to rapidly scan the absorbance of UV-VIS light by molecules in the water and estimate the concentration of the molecules based on the Beer-Lambert law. Strong correlation between [DOC] and light absorption has been used to provide algorithms that convert UV-VIS absorbance to [DOC] (Jollymore et al., 2012). FDOM sensors measure the intensity of fluorophores, molecules absorbing UV light and reemitting light at longer wavelengths. Streams and rivers containing terrestrial DOC have many fluorophores, and, thus, FDOM sensors can be used as a proxy to monitor [DOC] in freshwater systems (Downing et al., 2012; Wilson et al., 2013).

Although the two types of sensors have been employed to monitor $[\mathrm{DOC}]$ in various systems, several factors, such as $\mathrm{pH}$, turbidity, inorganic matter, and temperature, could limit the use of both sensors. While the effects of $\mathrm{pH}$ and inorganic materials (e.g., nitrate and iron) commonly observed in most natural watersheds are negligible (Weishaar et al., 2003), a change in water temperature and increased turbidity could reduce the accuracy of the sensor readings (Downing et al., 2012). Fluorescence decreases as temperature increases, which is known as thermal quenching (Watras et al., 2011), and particles significantly attenuate or interfere with the detection of UV-VIS and FDOM sensors (Downing et al., 2012; Jeong et al., 2012). While in situ fluorescence measurements in filtered stream water can provide a reliable proxy of stream [DOC] by overcoming interference due to particles, filter clogging has been reported to result in data loss during the later monitoring phase (Saraceno et al., 2009).

Although the UV-VIS and FDOM sensors have been used widely to estimate stream and river [DOC], to our knowledge, there is no study directly comparing the performance of the two types of sensors (Table 1). The sensors may have their own strengths and weaknesses as a proxy for monitoring stream [DOC], and, thus, the objective of this study is to compare the performance of UV-VIS and FDOM sensors as a proxy for $[\mathrm{DOC}]$ using laboratory experiments and in situ measurements in a temperate forest stream.

\section{Methods}

\subsection{Optical measurements using a UV-VIS and an FDOM sensor}

Laboratory experiments and in situ measurements were conducted with a UV-VIS sensor (carbo::lyser ${ }^{\mathrm{TM}}$, s::can Messtechnik GmbH, Austria) and an FDOM sensor (cyclops7, Turner Designs, USA). The UV-VIS sensor used in this study has two beams for autocalibration and a $5 \mathrm{~mm}$ optical path length, which is fitted to measurement ranges of $1-150 \mathrm{mg} \mathrm{L}^{-1}$ for TOC (total organic carbon) and $0.5-$ $75 \mathrm{mg} \mathrm{L}^{-1}$ for DOC (Jeong et al., 2012; Waterloo et al., 2006). It scans light absorbance from 220 to $720 \mathrm{~nm}$ and the sensor uses standardized spectral algorithms called "global calibration" to estimate the concentrations of organic carbon. DOC concentrations are estimated by correcting for absorbance by particles from the total absorbance of TOC on the basis of mathematical fitting derived from absorbance measurements at the multiple turbidity-related wavelengths in the visible range between 450 and $650 \mathrm{~nm}$ (Jeong et al., 2012). Since post-measurement correction can considerably increase the accuracy of the UV-VIS sensor, the unit of output (DOC) of the sensor before the post-measurement correction was expressed as RU (relative unit).

The FDOM sensor uses LED (light-emitting diode) as a light source, and the sensor uses the single excitation/emission pair, $325 / 470 \mathrm{~nm}$, with 120 and $60 \mathrm{~nm}$ excitation/emission band pass, respectively. Fluorescence intensity was normalized with quinine sulfate standards and expressed as quinine sulfate equivalent (QSE) in parts per billion. Quinine sulfate standards from 0 to $100 \mathrm{ppb}$ were prepared to calibrate the FDOM sensor by diluting $1000 \mathrm{ppm}$ of quinine sulfate stock solution, which was made by dissolving $1.21 \mathrm{~g}$ of quinine sulfate dihydrates in $1 \mathrm{~L}$ of $0.5 \mathrm{M}$ sulfuric acid.

A data logger (CR1000, Campbell science, USA) was used to collect the optical data of the sensors either every minute during laboratory experiments or every 5 min during in situ monitoring. Turbidity and temperature sensors were included in the UV-VIS sensor, and thus the water temperature and turbidity data were collected together with the proxy of [DOC]. The temperature and turbidity sensors inside the UV-VIS sensor were tested using an independently calibrated temperature sensor (HOBO U12 stainless temperature data logger, Onset Computer Corporation, USA) and a Hach 2100P Portable Turbidimeter (Hach Company, Loveland, USA).

In order to examine the feasibility of using the UVVIS and FDOM sensors as a proxy to estimate [DOC], three reference materials from the International Humic Substances Society (IHSS, http://www.humicsubstances.org) were tested; the Suwannee River natural organic matter (SRNOM: 2R101N), the Suwannee River humic acid standard II (SRHA: 2S101H), and the Suwannee River fulvic acid standard I (SRFA: 1S101F). A stock solution of each ref- 
Table 1. Previous studies using UV-VIS or FDOM sensors.

\begin{tabular}{|c|c|c|c|c|c|c|}
\hline $\begin{array}{l}\text { Sensor } \\
\text { type }\end{array}$ & $\begin{array}{l}\text { Sensor model } \\
\text { (company name) }\end{array}$ & Wavelengths & Location & Study year & Purpose & Reference \\
\hline UV-VIS & $\begin{array}{l}\text { Carbo::lyser } \\
\text { (s::can) }\end{array}$ & $220-720 \mathrm{~nm}$ & $\begin{array}{l}\text { Forested watershed, } \\
\text { South Korea }\end{array}$ & 2009-2010 & $\begin{array}{l}{[\mathrm{DOC}] \text { and }[\mathrm{POC}]} \\
\text { monitoring }\end{array}$ & Jeong et al. (2012) \\
\hline UV-VIS & Spectro::lyser (s::can) & $200-720 \mathrm{~nm}$ & $\begin{array}{l}\text { Forested (harvested) } \\
\text { watershed, British } \\
\text { Columbia, Canada }\end{array}$ & $2010-2011$ & {$[\mathrm{DOC}]$ monitoring } & Jollymore et al. (2012) \\
\hline UV-VIS & Spectro::lyser (s::can) & $200-732 \mathrm{~nm}$ & $\begin{array}{l}\text { Forested watershed, } \\
\text { Germany }\end{array}$ & $2010-2011$ & {$[\mathrm{DOC}]$ monitoring } & Strohmeier et al. (2013) \\
\hline UV-VIS & Spectro::lyser (s::can) & $220-742.5 \mathrm{~nm}$ & $\begin{array}{l}\text { Brackish marsh, North } \\
\text { Carolina, USA }\end{array}$ & 2011 & [DOC] monitoring & Etheridge et al. (2014) \\
\hline FDOM & $\begin{array}{l}\text { WETstar FDOM } \\
\text { fluorometer } \\
\text { (WETLabs) }\end{array}$ & $\begin{array}{l}\text { Ex } 370 \mathrm{~nm} / \\
\text { Em } 460 \mathrm{~nm}^{\mathrm{a}}\end{array}$ & $\begin{array}{l}\text { Agricultural watershed, } \\
\text { California, USA }\end{array}$ & 2008 & $\begin{array}{l}\text { Turbidity } \\
\text { correction }\end{array}$ & Saraceno et al. (2009) \\
\hline FDOM & $\begin{array}{l}\text { C3 Fluorometer } \\
\text { (Turner Designs); } \\
\text { UV Fluorometer } \\
\text { (SeaPoint) }\end{array}$ & $\begin{array}{l}\text { Ex } 340 \mathrm{~nm} / \\
\text { Em } 470 \mathrm{~nm} \text {; } \\
\text { Ex } 370 \mathrm{~nm} / \\
\text { Em } 440 \mathrm{~nm}^{\mathrm{b}}\end{array}$ & $\begin{array}{l}\text { Wetland-dominated } \\
\text { lakes, Wisconsin, USA }\end{array}$ & 2010 & $\begin{array}{l}\text { Temperature } \\
\text { correction }\end{array}$ & Watras et al. (2011) \\
\hline FDOM & $\begin{array}{l}\text { WETstar FDOM } \\
\text { fluorometer } \\
\text { (WETLabs) }\end{array}$ & $\begin{array}{l}\text { Ex } 370 \mathrm{~nm} / \\
\operatorname{Em~} 460 \mathrm{~nm}^{\mathrm{a}}\end{array}$ & $\begin{array}{l}\text { Forested watershed, } \\
\text { Vermont, USA }\end{array}$ & 2009 & {$[\mathrm{DOC}]$ monitoring } & Pellerin et al. (2012) \\
\hline FDOM & $\begin{array}{l}\text { UV fluorometer } \\
\text { (SeaPoint) }\end{array}$ & $\begin{array}{l}\text { Ex } 370 \mathrm{~nm} / \\
\text { Em } 440 \mathrm{~nm}^{\mathrm{b}}\end{array}$ & $\begin{array}{l}\text { Inflows to a lake, } \\
\text { Ireland }\end{array}$ & $2010-2011$ & $\begin{array}{l}\text { Temperature } \\
\text { correction }\end{array}$ & Ryder et al. (2012) \\
\hline FDOM & $\begin{array}{l}\text { Fluorometer } \\
\text { (Turner Designs, } \\
\text { WETLabs, Sea Point) }\end{array}$ & $\begin{array}{l}\text { Ex } 340-370 \mathrm{~nm} / \\
\text { Em } 430-460 \mathrm{~nm} \\
\text { (four sensors) }\end{array}$ & $\begin{array}{l}\text { The Connecticut River, } \\
\text { Connecticut, USA }\end{array}$ & 2010-2011 & $\begin{array}{l}\text { Temperature, color, } \\
\text { and turbidity correction }\end{array}$ & Downing et al. (2012) \\
\hline FDOM & $\begin{array}{l}\text { Cyclops } 7 \\
\text { (Turner Designs) }\end{array}$ & & $\begin{array}{l}\text { Bigelow Brook, } \\
\text { Massachusetts, USA }\end{array}$ & 2009-2010 & $\begin{array}{l}{[\mathrm{DOC}]} \\
\text { monitoring }\end{array}$ & Wilson et al. (2013) \\
\hline $\begin{array}{l}\text { UV-VIS } \\
\text { vs. } \\
\text { FDOM }\end{array}$ & $\begin{array}{l}\text { Carbo::lyser } \\
\text { (s::can) } \\
\text { vs. Cyclops } 7 \\
\text { (Turner Designs) }\end{array}$ & $\begin{array}{l}220-720 \mathrm{~nm} \\
\text { (UV-VIS); } \\
\text { Ex } 325 \mathrm{~nm} / \\
\text { Em } 470 \mathrm{~nm}^{\mathrm{a}}\end{array}$ & $\begin{array}{l}\text { Forest stream, } \\
\text { South Korea }\end{array}$ & 2012-2013 & $\begin{array}{l}\text { UV-VIS } \\
\text { vs. FDOM } \\
\text { Sensor comparison }\end{array}$ & This study \\
\hline
\end{tabular}

a Single excitation/emission wavelength pair, ${ }^{\mathrm{b}}$ center wavelength.

erence material was made by dissolving $500 \mathrm{mg}$ of SRNOM, and $100 \mathrm{mg}$ of the other materials in a $100 \mathrm{~mL}$ volumetric flask with deionized water (DI), followed by filtration through a glass fiber filter (GF / F, Whatman; nominal pore size $0.7 \mu \mathrm{m}$ ). The ranges of [DOC] examined were 0 to $5.1,0$ to 2.1 , and 0 to $4.1 \mathrm{mg} \mathrm{L}^{-1}$ for SRNOM, SRHA, and SRFA, respectively. The [DOC] was measured with a Shimadzu $V_{\mathrm{CPH}}$ TOC analyzer (Shimadzu Corporation, Japan) based on the high-temperature combustion method for measuring non-purgeable organic carbon in acidified samples $(\sim \mathrm{pH} 2)$. Unless specified, the filtered [DOC] measured by the Shimadzu analyzer is presented as "lab DOC" in this article. The accuracy of the Shimadzu analyzer was verified by analyzing a quality check (QC) solution (ERA, Colorado, USA) at a concentration similar to the sample [DOC]. The measurement error for a QC of $4.8 \mathrm{mg} \mathrm{L}^{-1}$ was $3 \%$ on average and $<0.1 \mathrm{mg} \mathrm{L}^{-1}$ for a $\mathrm{QC}$ of $0.5 \mathrm{mg} \mathrm{L}^{-1}$.

\subsection{Temperature and turbidity correction}

During the laboratory experiments, UV-VIS and FDOM sensors were submerged in a $10 \mathrm{~L}$ glass beaker containing $10 \mathrm{~L}$ of DI with black-cover books lying below it to minimize light reflection. The stock solution prepared with the IHSS stan- dards was added to the beaker so that the final [DOC] of the solutions was within the range of $0-5.1 \mathrm{mg} \mathrm{L}^{-1}$. In order to simulate field conditions, about $20 \mathrm{~L}$ of stream water was used for temperature and turbidity correction. The stream water had been collected from a forest watershed, as detailed in Sect 2.3, at peak discharge when the typhoon Nakri hit South Korea on August 2nd in 2014. The water was collected using precombusted $2 \mathrm{~L}$ glass bottles and was kept frozen before the experiment. The [DOC] of the thawed and filtered $(\mathrm{GF} / \mathrm{F})$ stream water was $3.4 \mathrm{mg} \mathrm{L}^{-1}$ and was used to test the effects of temperature on UV-VIS and FDOM sensors at $6-26^{\circ} \mathrm{C}$.

Artificial turbid stream water was also prepared by adding $270 \mathrm{~g}$ of soils collected from the study site (see Sect. 2.3) to $10 \mathrm{~L}$ of the stream water and extracting DOC from the soils for about $48 \mathrm{~h}$ to preclude additional organic matter dissolved from the soil (Downing et al., 2012; Jeong et al., 2012). The soils were collected from the study watershed at $0-15 \mathrm{~cm}$ depth and were air-dried and sieved $(<2 \mathrm{~mm})$ before use. The lab DOC of the resulting solution was $12.3 \mathrm{mg} \mathrm{L}^{-1}$ and was used to prepare a series of solutions of different lab DOC to evaluate temperature effects on the sensor readings. These ranged from 1.1 to $10.5 \mathrm{mg} \mathrm{L}^{-1}$ and were created by mixing with DI. 
Linear regression between UV-VIS sensor and temperature was used to estimate the temperature correction factor for UV-VIS sensor outputs, $r_{\mathrm{UV}, \mathrm{T}}$ (Eq. 1). Since the difference in the slopes of the UV sensor against temperature was not statistically significant (Fig. 2d), the mean of the two slopes $(\alpha)$ was used to calculate the UV-VIS sensor outputs at $20^{\circ} \mathrm{C}\left(\mathrm{UV}-\mathrm{VIS}_{20}\right)$ (Eq. 1).

$\mathrm{UV}-\mathrm{VIS} \mathrm{S}_{20}=\mathrm{UV}-\mathrm{VIS} \mathrm{m}_{\mathrm{m}}+\alpha\left(20-T_{\mathrm{m}}\right)$,

where $T_{\mathrm{m}}$ is the temperature at which UV-VIS sensor outputs were measured (UV-VIS $S_{m}$ ).

The temperature correction of the FDOM sensor was conducted following the method of Watras et al. (2011).

$\mathrm{FDOM}_{20}=\mathrm{FDOM}_{\mathrm{m}} /\left[1+\rho\left(T_{\mathrm{m}}-20\right)\right]$,

where $\mathrm{FDOM}_{20}$ is a predicted $\mathrm{FDOM}$ at $20^{\circ} \mathrm{C}, \mathrm{FDOM}_{\mathrm{m}}$ is the measured FDOM at temperature $\left(T_{\mathrm{m}}\right), \rho$ is temperature coefficient $\left({ }^{\circ} \mathrm{C}^{-1}\right)$, and $\mathrm{T}$ is temperature $\left({ }^{\circ} \mathrm{C}\right)$ (Eq. 2$)$.

The turbidity of the solution was measured using aliquots and the sensor readings of the artificial turbid water were recorded every minute while the solution was continuously stirred with a magnetic bar during the experiments. The sensor outputs of the turbid water were compared with those of the filtered water to calculate the $r_{\mathrm{p}}$ (Eqs. 3 and 4) (Downing et al., 2012). The maximum turbidity of the solution was 973.3 NTU to cover most of the extreme events in streams and rivers (Downing et al., 2012; Jeong et al., 2012; Kim et al., 2013).

$r_{\mathrm{UV}, \mathrm{p}}=\left(\mathrm{UV}-\mathrm{VIS} \mathrm{S}_{\mathrm{m}}\right) /\left(\mathrm{UV}-\mathrm{VIS}_{\mathrm{f}}\right)$

$r_{\mathrm{FDOM}, \mathrm{p}}=\mathrm{FDOM}_{\mathrm{m}} / \mathrm{FDOM}_{\mathrm{f}}$,

where UV-VIS $\mathrm{m}_{\mathrm{m}}$ and $\mathrm{FDOM}_{\mathrm{m}}$ are measured sensor outputs and UV-VIS $\mathrm{f}$ and $\mathrm{FDOM}_{\mathrm{f}}$ are the sensor outputs of solution filtered using GF / F filters. Given that the slopes of UVVIS outputs against lab DOC were not statistically different (Jeong et al., 2012), $r_{\mathrm{UV}, \mathrm{p}}$ can be calculated using linear interpolation for any turbidity of any lab DOC. Thus, the raw sensor outputs were corrected for temperature and turbidity using the following equations:

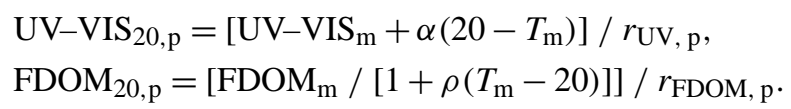

\subsection{In situ measurements of the sensors in a forest stream}

The UV-VIS, FDOM, and temperature sensors were deployed in a second-order stream from a forested watershed, Bukmoongol Watershed (BW; $\left.35.0319^{\circ} \mathrm{N}, 127.6050^{\circ} \mathrm{E}\right)$ at Mt. Baekwoon, located in Gwangyang city, South Korea. The watershed is 33.3 ha in size and composed of $70 \%$ coniferous and $30 \%$ deciduous forests. Major tree species are Pinus densiflora, Pinus rigida, Cryptomeria japonica, Pinus taeda, and Carpinus laxiflora. Mean annual temperature is $14.4^{\circ} \mathrm{C}$ and mean annual precipitation is $1531 \mathrm{~mm}(1981-2010)$ at the weather station located in Suncheon (Korea Meteorological Administration, www.kma.go.kr), $\sim 20 \mathrm{~km}$ away from Mt. Baekwoon. Bedrock is mainly composed of granite and partially of gneiss, and sandy loam and clay loam constitute much of its soil (Park et al., 2000).

The use of the sensors as a [DOC] proxy was examined during three storm events: 27-28 October 2012 (storm 1), 10-11 November 2012 (storm 2), and 23-24 April 2013 (storm 3). Both sensors were submerged next to each other in the water in the ponding basin of a U-shaped weir. UVVIS sensor was deployed with the sensor head facing the streambed to minimize the settling of particles, and compressed air cleaned the sensor head right before the measurements to prevent sediment accumulation. The FDOM sensor was deployed with its head directed at the streambed to minimize light reflection. Two abnormal UV-VIS data points out of a total of 1088 data points were filtered off when they remained larger than mean +3 standard deviation for $1 \mathrm{~h}$ compared to consecutive measurements; this could be due to stochastic disturbances by leaves or debris (Jeong et al., 2012). The two outliers were replaced by the average of neighboring two data points.

During the in situ deployment of the sensors, discrete stream water samples were collected every 1 to $4 \mathrm{~h}$ from the start to the end of each event. Samples were frozen immediately after sampling and transported on ice to the laboratory. Then, they were filtered through a GF / F filter and lab DOC concentrations were measured to compare them with the sensor outputs. The DOC concentrations of several frozen samples were compared to those of refrigerated samples and the difference was less than $0.1 \mathrm{mg} \mathrm{L}^{-1}$ $(p=0.46)$. Linear regression models were used to estimate relationships between sensor outputs and lab DOC. Statistical analyses were conducted with the R statistical program (http://www.r-project.org/) and considered significant when $p<0.05$.

\section{Results and discussion}

\subsection{Laboratory experiments}

\subsubsection{Sensor signals vs. lab DOC of reference materials}

Laboratory experiments of UV-VIS and FDOM sensors on SRNOM, SRHA, and SRFA exhibited strong linear relationships between the sensor signals and lab DOC $\left(R^{2}: 0.98\right.$ to $1, p<0.01$ ), although the slopes were not identical among the dissolved organic materials (Fig. 1). The slope of UVVIS signals of SRHA was significantly different from that of SRNOM and SRFA (Fig. 1a), and the slope of the FDOM signals of SRFA was significantly different from that of SRNOM and SRHA (Fig. 1b). 

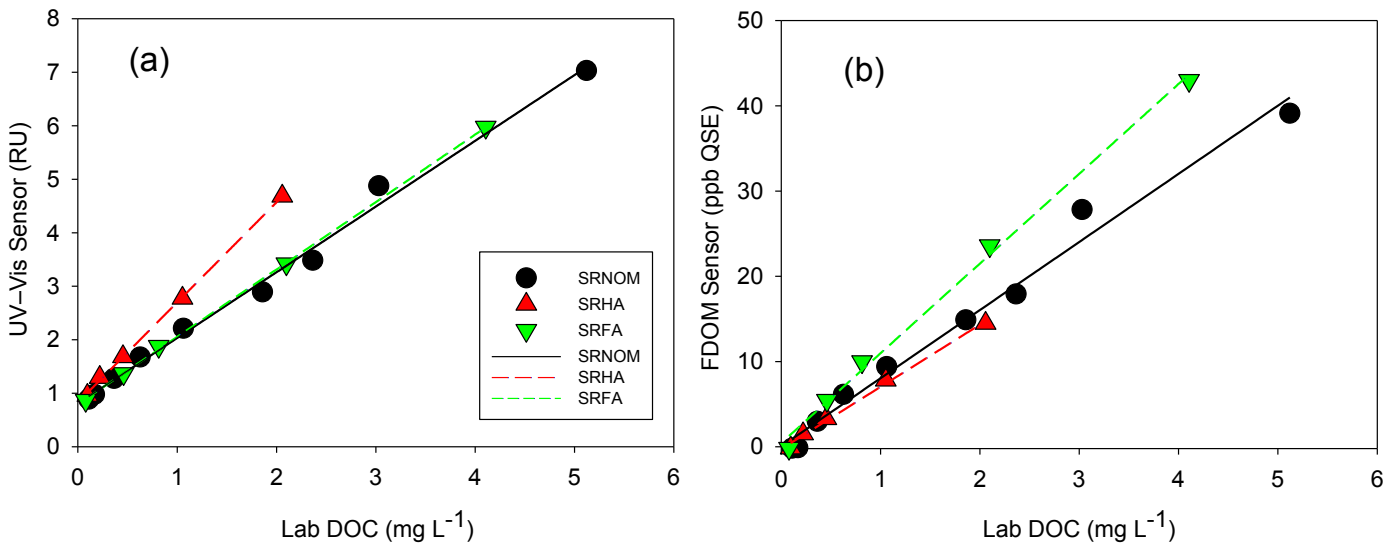

Figure 1. Relationship between (a) UV-VIS (RU: relative units) and (b) FDOM sensor readings and DOC concentrations of IHSS standard reference material (SRNOM, SRHA, and SRFA) measured by Shimadzu TOC analyzer (lab DOC) at a water temperature of between 17 and $19^{\circ} \mathrm{C}$. The $R^{2}$ of the linear regression lines was 0.98 to 1.00 .
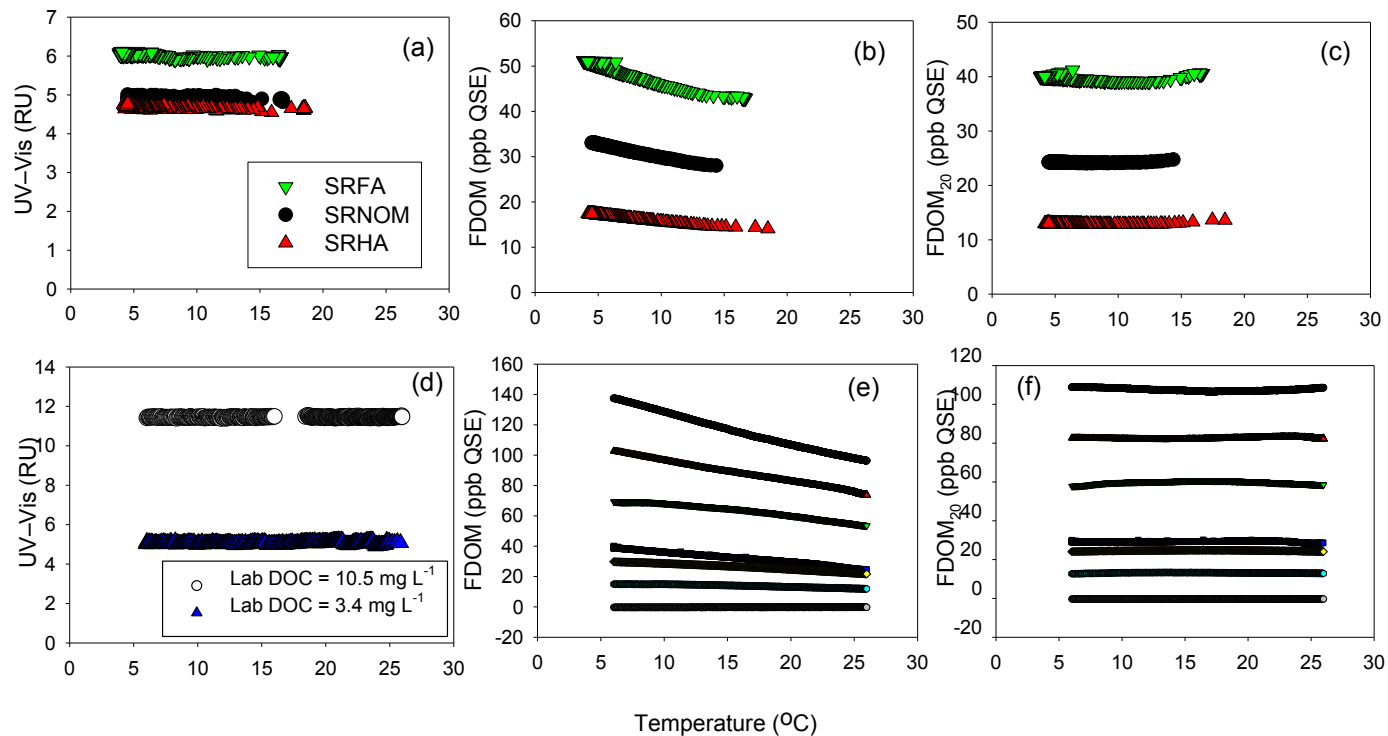

Figure 2. Plots of UV-VIS (RU: relative units), FDOM, and $\mathrm{FDOM}_{20}\left(\mathrm{FDOM}\right.$ signals corrected for $20^{\circ} \mathrm{C}$ ) against temperature for the IHSS standard reference materials (SRFA, SRNOM, and SRHA) (a, b, c), and for the forest stream water (d, e, f). The lab DOC of SRFA, SRNOM, and SRHA were 4.1, 3.0, and $2.1 \mathrm{mg} \mathrm{L}^{-1}$, respectively, and the seven lines in (e) and (f) represent lab DOC of 10.5, 7.2, 5.2, 3.4, 2.1, 1.1, and $0 \mathrm{mg} \mathrm{L}^{-1}$ from top to bottom. All slopes were statistically significant $(p<0.01)$ except (c) the three lines of $\mathrm{FDOM}_{20}(p>0.36)$ and (f) lab DOC of $3.4 \mathrm{mg} \mathrm{L}^{-1}(p=0.09)$.

SUVA $_{254}$ (specific UV absorbance at $254 \mathrm{~nm}$ ) of SRHA $(1 \mathrm{~S} 101 \mathrm{H})$ was higher than that of SRFA $(1 \mathrm{~S} 101 \mathrm{~F})$ and SRNOM (1R101N), indicating that SRFA and SRNOM contain more non-UV-absorbing carbon (Alberts and Takács, 2004). In contrast, relative fluorescence intensities of SRFA were higher than those of SRHA $(1 \mathrm{~S} 101 \mathrm{H})$ and SRNOM (1R101N) (Alberts and Takács, 2004). This suggests that the reliability of the UV-VIS and FDOM sensors can be dependent on the proportion of light-absorbing functional groups in DOC and the degree of charge-transfer interactions between the electron donor (e.g., hydroxy benzene) and acceptor (e.g., quinoid) groups (Del Vecchio and Blough, 2004).

Humic acids and fulvic acids are the major fraction of DOC in natural waters (Del Vecchio and Blough, 2004), covering about $60 \%$ of aquatic DOC with a humic acid to fulvic acid ratio of $1: 3$ in the median freshwater (Perdue and Ritchie, 2014). Although DOC composition can remain relatively constant across seasons, slightly increased fluorescence per unit absorbance was reported in a forest stream in the northeastern US (Wilson et al., 2013). Since stream and riverine DOC composition can shift following storms (Fell- 
man et al., 2009), a comparison of monitored sensor signals with lab DOC of periodically collected samples is warranted.

\subsubsection{Temperature effects on optical measurements}

The UV-VIS sensor outputs showed little variability with temperature change (slope: 0.009 to $-0.004 ; R^{2}: 0.22$ to $0.54 ; p<0.01)$ in SRNOM, SRHA, and SRFA solutions (Fig. 2a) as well as in the forest stream water (Fig. 2d; slope: 0.001 to $0.002 \mathrm{RU}^{\circ} \mathrm{C}^{-1} ; R^{2}: 0.03$ to $0.04 ; p<0.01$ ). The slopes of the UV-VIS sensor outputs against temperature were less than $0.01 \mathrm{RU}^{\circ} \mathrm{C}^{-1}$, indicating that the effect of temperature on the UV-VIS sensor was negligible. Even if the temperature of the forest stream water increased by $20^{\circ} \mathrm{C}$, the sensor outputs would increase only by $\sim 0.03 \mathrm{RU}$, which is less than $1 \%$ of sensor readings of the forest stream (Fig. 2d). Therefore, it may be advantageous to use the UVVIS sensor in remote areas with a large temperature fluctuation (Jollymore et al., 2012). For example, the UV-VIS sensor was used for continuous monitoring of [DOC] in a forest stream where stream temperature varied from near 0 to $\sim 25^{\circ} \mathrm{C}$ (Jeong et al., 2012).

In contrast, FDOM signals can be significantly affected by temperature changes because the temperature increase is likely to return an excited electron to its ground state by radiationless decay, resulting in a reduced fluorescence emission intensity (Watras et al., 2011). We observed strong negative correlations of the FDOM sensor with temperature in the reference materials as well as in the whole range of DOC concentrations from 1.1 to $10.5 \mathrm{mg} \mathrm{L}^{-1}$ in the forest stream (slope: -0.17 to -2.07 (ppb QSE) ${ }^{\circ} \mathrm{C}^{-1} ; R^{2}: 0.97$ to 0.99 ; $p<0.001$ ), decreasing by $\sim 1.4 \%$ in ppb QSE per $1{ }^{\circ} \mathrm{C}$ increase (Fig. 2b, e). This result is consistent with the former studies showing that FDOM signals decreased by an average of $0.8-1.5 \%$ per $1{ }^{\circ} \mathrm{C}$ increase over the range of $\sim 1$ to $25^{\circ} \mathrm{C}$ (Downing et al., 2012; Watras et al., 2011).

A study on fluorescence of wetland-dominated lakes demonstrated that slope of the fluorescence against temperature increased as concentration decreased (Watras et al., 2011), and the same pattern was observed in this study (Fig. 2e). The temperature coefficient, $\rho\left({ }^{\circ} \mathrm{C}^{-1}\right)$, was estimated to be $-0.017 \pm 0.004$ (mean $\pm \mathrm{SD}$ ) for the solutions of lab DOC from 1.1 to $10.5 \mathrm{mg} \mathrm{L}^{-1}$ at $20^{\circ} \mathrm{C}$. Given that the extent of thermal quenching is related to the exposure of the fluorophores to the heat source (Baker, 2005), the concentration of fluorophores can increase as [DOC] increases, and thus more fluorophores at high DOC concentrations are prone to thermal quenching as temperature increases. This suggests that temperature correction of FDOM sensor outputs would be critical, especially for water of relatively high DOC concentrations. The degree of thermal quenching is also dependent on the components of DOC such that tryptophanlike fluorophores exhibit strong thermal quenching properties compared to humic-like or fulvic-like fluorophores (Baker, 2005). Thus, it warrants further study to determine whether

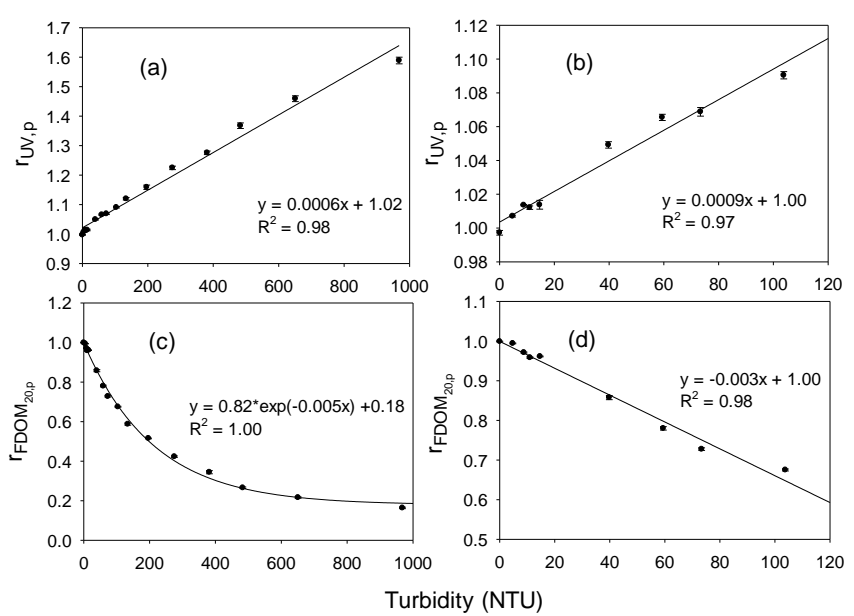

Figure 3. Relationships between (a, b) $r_{U V}, p$ and turbidity, and those between $(\mathbf{c}, \mathbf{d}) r_{\mathrm{FDOM}} 20, \mathrm{p}$ and turbidity for the forest stream water (lab DOC $=12.3 \mathrm{mg} \mathrm{L}^{-1}$ ). Note that the graphs $(\mathbf{b})$ and $(\mathbf{d})$ were drawn for turbidity less than 120 NTU only to establish a regression equation for turbidity correction of in situ monitoring of the forest stream.

the accuracy of the FDOM sensor decreases in water containing high amounts of tryptophan-like compounds.

These results suggest that the FDOM sensor requires temperature correction to correctly estimate [DOC], especially in streams where $[\mathrm{DOC}]$ is relatively high and temperature varies a lot. After the temperature correction, $\mathrm{FDOM}_{20}$ did not change significantly as temperature increased (Fig. 2c, f), demonstrating that proper temperature correction allows the FDOM sensor to be used as a proxy of [DOC] in streams that are also continuously monitored for water temperature.

\subsubsection{Turbidity effects on optical measurements}

The UV-VIS sensor outputs increased as turbidity increased, and, thus, $r_{\mathrm{UV}, \mathrm{p}}$ had a positive linear relationship over 0 to $\sim 1000 \mathrm{NTU}$ of turbidity (slope: $0.0006, R^{2}: 0.98$, $p<0.001$ ), resulting in a $\sim 70 \%$ increase in UV-VIS sensor signals at 1000 NTU of the forest stream water (Fig. 3). The slope of $r_{\mathrm{UV}}$, p against turbidity was slightly higher (0.0009) over the range of $0-100$ NTU of turbidity, suggesting that $r_{\mathrm{UV}, \mathrm{p}}$ was more sensitive in relatively low turbidity. However, the change in $r_{\mathrm{UV}} \mathrm{p}$ was only $\sim 10 \%$ for the forest stream water, even at 100 NTU .

In contrast, FDOM outputs decreased exponentially, as turbidity increased from 0 to $\sim 1000$ NTU. Values of $r_{\text {FDOM, }}$ also changed exponentially in the whole range of turbidity and decreased linearly at low turbidity (Fig. 3c, d; $p<0.001$ ). About $34 \%$ of FDOM signals were attenuated at $\sim 100 \mathrm{NTU}$ and $84 \%$ of FDOM signals at $\sim 1000 \mathrm{NTU}$, which was similar to the results of Downing et al. (2012). Although about 80-90\% FDOM signals were attenuated at $\sim 1000$ NTU using the Elliott Soil (IHSS standard), the at- 

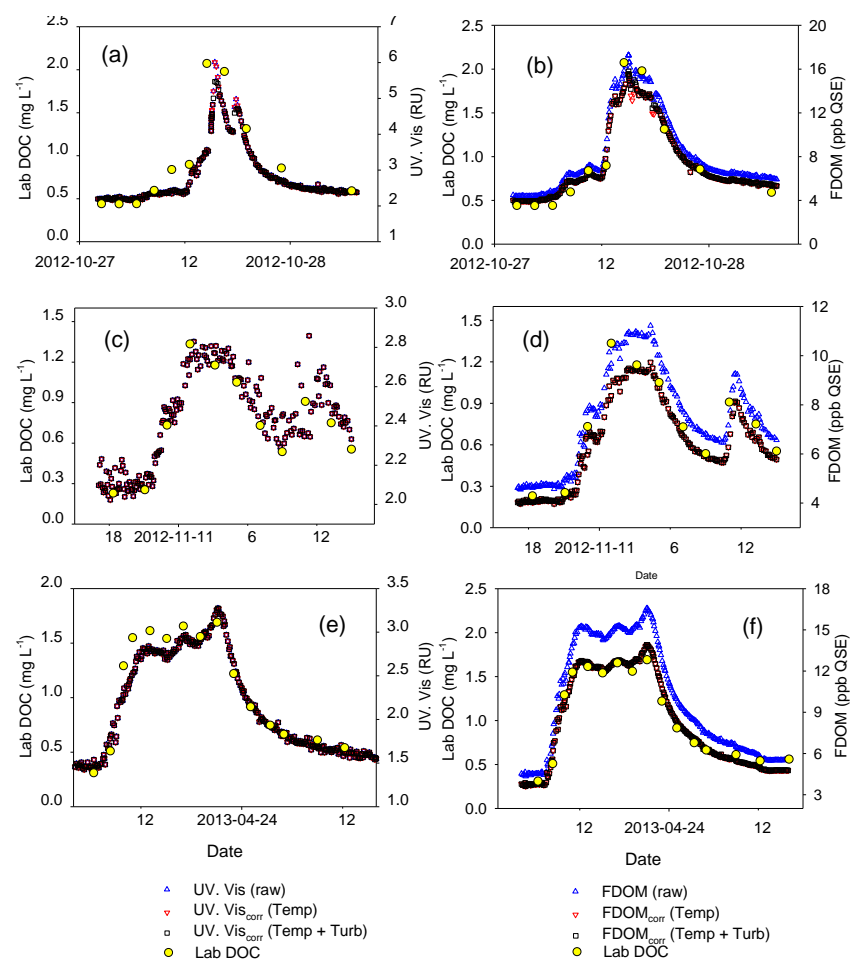

Figure 4. In situ UV-VIS and FDOM sensor outputs of raw data, corrected for temperature at $20^{\circ} \mathrm{C}$ (UV-VIS corr (Temp) and $\mathrm{FDOM}_{\text {corr }}$ (Temp)), for temperature at $20^{\circ} \mathrm{C}$ and turbidity (UV$\mathrm{VIS}_{\text {corr }}\left(\right.$ Temp + Turb), and for FDOM $_{\text {corr }}$ (Temp + Turb)), compared with lab DOC. The precipitation of three storm events was (a, b) 40.5 , (c, d) 19.5 , and (e, f) $56.0 \mathrm{~mm}$.

tenuation of FDOM signals was just $10-20 \%$ at a turbidity of less than 50 NTU (Downing et al., 2012). Considering that the slope of light attenuation varies with the particle size distribution (Boss et al., 2001), soils with different particle compositions may result in different attenuation effects.

Turbidity can increase to more than 1000 NTU during strong storms in upstream forested watersheds in South Korea although turbidity was lower than 1000 NTU throughout the year in most streams and rivers (Kim et al., 2013). Given the strong dependency of DOC estimation on turbidity in the UV-VIS sensor and the exponential decrease in FDOM outputs due to increased turbidity, correction for turbidity is a critical step for the sensors to be used as a proxy for [DOC]. This could be even more critical in streams with relatively high slopes under Asian monsoon climates. Since stream turbidity can be a function of size of particles and soil mineralogy of a watershed (Hur and Jung, 2009), site-specific correction for turbidity is necessary.
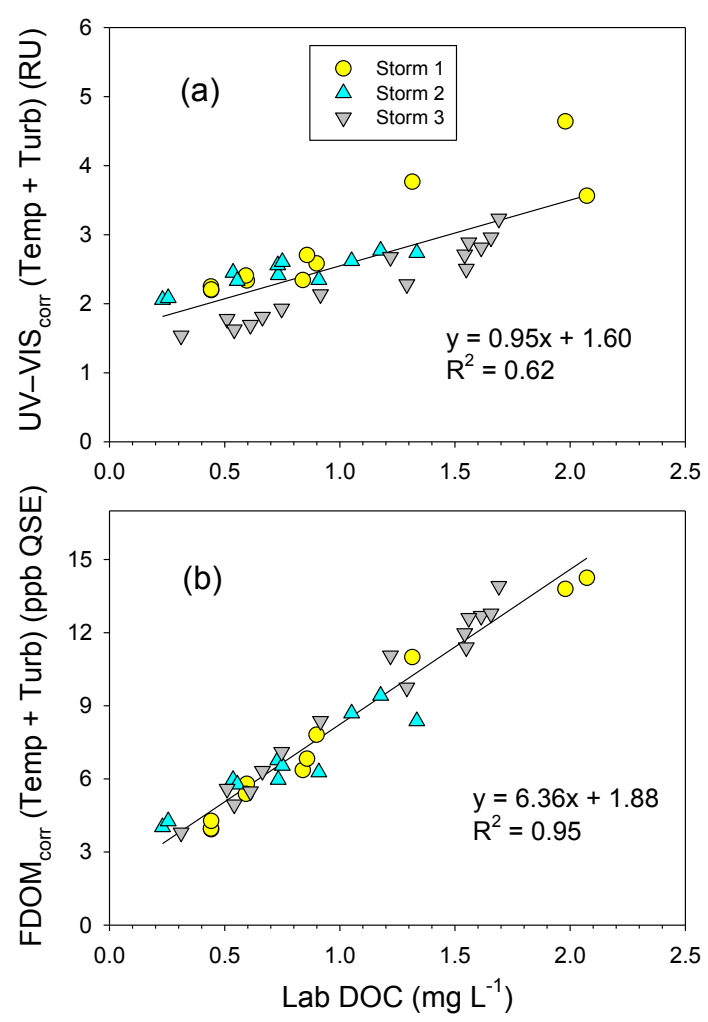

Figure 5. Comparison between lab DOC of the three storm events (Fig. 4) and (a) UV-VIS and (b) FDOM sensor outputs corrected for temperature at $20^{\circ} \mathrm{C}$ and turbidity. Storm 1: 27-28 October 2012; storm 2: 10-11 November 2012; and storm 3: 23-24 April 2013.

\subsection{In situ measurements of UV-VIS and FDOM sensors}

The UV-VIS and FDOM sensors followed the changes in [DOC] in the three storms (Fig. 4) in which water temperature ranged from 8.2 to $13.8^{\circ} \mathrm{C}$. The precipitation of the three storm events was $40.5,19.5$, and $56.0 \mathrm{~mm}$, which only increased turbidity up to $\sim 30$ NTU. Since the variation in temperature and turbidity was relatively small, the in situ data of the sensors corrected for temperature and turbidity (Eqs. 5 and 6) were similar to the raw signals of the sensors, except for the temperature-corrected FDOM signals (Fig. 4).

While the UV-VIS signals did not change significantly after temperature and turbidity corrections, the FDOM signals decreased after temperature correction because water temperature was consistently lower than the reference temperature of $20^{\circ} \mathrm{C}$, with a negligible change for turbidity correction (Fig. 4). The correlation coefficient of linear regression between FDOM $_{\text {corr }}\left(\right.$ temp + turb) and lab DOC $\left(R^{2}=0.95\right)$

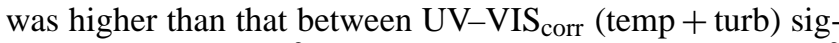
nals and lab DOC $\left(R^{2}=0.62\right)$ (Fig. 5). The relatively low $R^{2}$ of the UV-VIS sensor was due to the two outliers of storm 1. We postulate that the UV-VIS sensor outputs are sensitive to 
turbidity sensor outputs within the system since both of them appear tightly connected in global calibration.

The three storm events were not strong in terms of precipitation intensity and did not capture a large variation in temperature and turbidity in the field, and this is a limitation of this study. However, this can be also interpreted as meaning that the sensors can be employed to provide reliable, highresolution data for base flow conditions. Although it has been demonstrated that the sensors can be corrected for temperature and turbidity to be used as a proxy of [DOC], there are several other factors that should be considered for successful application of the sensors in the field.

The sensors use absorbance and fluorescence of light by dissolved organic matter (DOM), and thus the DOM with optical properties may not represent the entire DOM pool although fluorophores correlate well with diverse, known compounds in other riverine environments (Stubbins et al., 2014). The single excitation and emission pair that the FDOM sensor used in this study (Table 1) estimates the intensity of fluorescence of humic-like DOM (Stedmon and Markager, 2005). If the dominant DOM composition of water samples reacts to different excitation and emission pairs, for example, tryptophan-like components, which absorb at $280 \mathrm{~nm}$ and emit at $344 \mathrm{~nm}$ of wavelength (Stedmon and Markager, 2005), the FDOM sensor may underestimate stream [DOC]. However, considering that $\sim 80 \%$ of stream DOC released from the forested watershed was terrestrial humic components estimated by parallel factor (PARAFAC) analysis (unpublished data), the FDOM sensor can be effectively employed as a proxy of [DOC] after temperature and turbidity correction. Nonetheless, a comparison with the [DOC] of periodically collected samples would still be necessary since the proportional change in chromophores and fluorophores in humic materials during intensive storms could result in changes in sensor outputs.

Although we tested two specific models of UV-VIS and FDOM sensors, multiple models are available and we did not address the variability of many sensors or variability within a model line. Sensor-specific as well as site-specific calibration would be necessary to use the sensors as a proxy of [DOC], considering that each sensor reacts differently to a range of temperatures and turbidities. For example, four types of FDOM sensors showed a different ratio of attenuation to changes in turbidity although they all showed increasing trends of attenuation with increased turbidity (Downing et al., 2012). FDOM sensors with an open path responded more strongly to turbidity changes than those with a closed path (Downing et al., 2012).

The inner filter effect (IFE) could be a problem in obtaining correct fluorescence data of stream water if the stream has a relatively high [DOC] with high aromaticity. However, a study highlighted that common rivers and streams have minor IFE effects from dissolved organic matter (Downing et al., 2012). It is unlikely that FDOM signals need to be cor- rected for IFE in the forest stream, where [DOC] was less than $3 \mathrm{mg} \mathrm{L}^{-1}$.

Maintaining clean surfaces on the light sources of the sensors during long-term monitoring is an important practical consideration in ensuring data quality since particles can cause light absorption or scattering (Etheridge et al., 2013). Algae which commonly occur in lakes or large rivers during summer in South Korea could interfere with light path of optical sensors. Although algae were not observed at the study site, the surface of the sensor needed to be cleaned periodically because it might still be coated with inorganic materials. The UV-VIS sensor uses air bubbles to prevent the accumulation of particles in the light beam path, and some advanced FDOM sensors have an auto-cleaning wiper. However, the frequency of field checks may still need to be decided depending on site characteristics.

\section{Conclusions and implications}

A variety of organic compounds can absorb UV-Visible light and reemit light at a longer wavelength, and this optical property can be used to monitor stream [DOC] by UV-VIS and FDOM sensors. The credibility as well as continuity of the field DOC data may improve significantly due to the recent advances in sensor technology as well as wireless remote online connections if combined with field-based calibration processes. Terrestrially derived humic materials have many fluorophores, and thus UV-VIS and FDOM sensors have a strong potential to be used for continuous monitoring of [DOC] in streams of forested watersheds. However, the results shown in this study suggest that temperature and turbidity correction using site-specific and sensor-specific information is critical to reducing inaccurate sensor responses to large temporal fluctuations in temperature and turbidity, particularly during strong storm events, when turbidity can increase by a few orders of magnitude. While the sensor correction for temperature is relatively straightforward, that for turbidity is not simple because turbidity can be affected by particle size and soil mineralogy. More than $80 \%$ of light can be attenuated at turbidity $>1000$ NTU in an FDOM sensor. Although refined calibration with quantified particle size distribution may improve the accuracy of the sensors as a [DOC] proxy, the results suggest that the optical sensors should be used with caution, especially for turbid waters (e.g., $>\sim 400 \mathrm{NTU}$ ), where sensitivity of the sensors quickly decreases due to the attenuation of light. We speculate that the same problem can occur to the UV-VIS sensor although $r_{\mathrm{UV}, \mathrm{p}}$ did not become saturated within $\sim 1000$ NTU. The linear $r_{\mathrm{UV}}$, p could possibly be due to the sensor outputs already having been adjusted within the sensor by global calibration. Sensors connected to a filtration system may still provide a proxy of $[\mathrm{DOC}]$ even in the highly turbid waters (Saraceno et al., 2009); however, clogging can hamper the wide-spread application of the sensors. Shifts in composition 
of fluorophores also need to be carefully tracked since light absorbance and fluorescence can vary as the concentrations of dominant fluorophores change. Thus, analyses of UV-VIS and fluorescence spectra of periodically collected water samples are also recommended in addition to laboratory [DOC] measurement for the sensors to be used as a [DOC] proxy.

Acknowledgements. We would like to thank Yera Shin, EunByul Ko, and Young-Joon Jeon at Seoul National University for lab analyses and discussions. We also thank staff at Seoul National University Forest. This paper was supported by the Basic Science Research Program, through the National Research Foundation of Korea (NRF), funded by the Ministry of Education, Science and Technology (2011-0024706). It was also supported by the Korea Forest Service (500-20120415).

Edited by: T. J. Battin

\section{References}

Aitkenhead, J. A. and McDowell, W. H.: Soil C : N ratio as a predictor of annual riverine DOC flux at local and global scales, Global Biogeochem. Cy., 14, 127-138, 2000.

Alberts, J. J. and Takács, M.: Total luminescence spectra of IHSS standard and reference fulvic acids, humic acids and natural organic matter: comparison of aquatic and terrestrial source terms, Org. Geochem., 35, 243-256, 2004.

Baker, A.: Thermal fluorescence quenching properties of dissolved organic matter, Water Res., 39, 4405-4412, 2005.

Boss, E., Pegau, W. S., Gardner, W. D., Zaneveld, J. R. V., Barnard, A. H., Twardowski, M. S., Chang, G. C., and Dickey, T. D.: Spectral particulate attenuation and particle size distribution in the bottom boundary layer of a continental shelf, J. Geophys. Res.Oceans, 106, 9509-9516, 2001.

Del Vecchio, R. and Blough, N. V.: On the origin of the optical properties of humic substances, Environ. Sci. Technol., 38, 38853891, 2004.

Di Toro, D. M., Allen, H. E., Bergman, H. L., Meyer, J. S., Paquin, P. R., and Santore, R. C.: Biotic ligand model of the acute toxicity of metals, 1. Technical basis, Environ. Toxicol. Chem., 20, 23832396, 2001.

Downing, B. D., Pellerin, B. A., Bergamaschi, B. A., Saraceno, J. F., and Kraus, T. E. C.: Seeing the light: The effects of particles, dissolved materials, and temperature on in situ measurements of DOM fluorescence in rivers and streams, Limnol. Oceanogr.Methods, 10, 767-775, 2012.

Etheridge, J. R., Birgand, F., Burchell, M. R., and Smith, B. T.: Addressing the Fouling of In Situ Ultraviolet-Visual Spectrometers Used to Continuously Monitor Water Quality in Brackish Tidal Marsh Waters, J. Environ. Qual., 42, 1896-1901, 2013.

Etheridge, J. R., Birgand, F., Osborne, J. A., Osburn, C. L., Burchell, M. R., II, and Irving, J.: Using in situ ultraviolet-visual spectroscopy to measure nitrogen, carbon, phosphorus, and suspended solids concentrations at a high frequency in a brackish tidal marsh, Limnol. Oceanogr.-Methods, 12, 10-22, 2014.

Fellman, J. B., Hood, E., Edwards, R. T., and D'Amore, D. V.: Changes in the concentration, biodegradability, and fluorescent properties of dissolved organic matter during stormflows in coastal temperate watersheds, J. Geophys. Res.-Biogeosci., 114, G01021, doi:10.1029/2008JG000790, 2009.

Hinton, M. J., Schiff, S. L., and English, M. C.: The significance of storms for the concentration and export of dissolved organic carbon from two Precambrian Shield catchments, Biogeochemistry, 36, 67-88, 1997.

Hur, J. and Jung, M. C.: The effects of soil properties on the turbidity of catchment soils from the Yongdam dam basin in Korea, Environ. Geochem. Health, 31, 365-377, 2009.

Hur, J., Hang Vo-Minh, N., and Lee, B.-M.: Influence of upstream land use on dissolved organic matter and trihalomethane formation potential in watersheds for two different seasons, Environ. Sci. Pollut. Re., 21, 7489-7500, 2014.

Jeong, J. J., Bartsch, S., Fleckenstein, J. H., Matzner, E., Tenhunen, J. D., Lee, S. D., Park, S. K., and Park, J. H.: Differential storm responses of dissolved and particulate organic carbon in a mountainous headwater stream, investigated by high-frequency, in situ optical measurements, J. Geophys. Res.-Biogeosci., 117, G03013, doi:10.1029/2012JG001999, 2012.

Jollymore, A., Johnson, M. S., and Hawthorne, I.: Submersible UVVis spectroscopy for quantifying streamwater organic carbon dynamics: Implementation and challenges before and after forest harvest in a headwater stream, Sensors, 12, 3798-3813, 2012.

Kim, J.-K., Jung, S., Eom, J.-s., Jang, C., Lee, Y., Owen, J. S., Jung, M.-S., and Kim, B.: Dissolved and particulate organic carbon concentrations in stream water and relationships with land use in multiple-use watersheds of the Han River (Korea), Water Internat., 38, 326-339, 2013.

Koehler, A. K., Murphy, K., Kiely, G., and Sottocornola, M.: Seasonal variation of DOC concentration and annual loss of DOC from an Atlantic blanket bog in South Western Ireland, Biogeochemistry, 95, 231-242, 2009.

Morris, D. P., Zagarese, H., Williamson, C. E., Balseiro, E. G., Hargreaves, B. R., Modenutti, B., Moeller, R., and Queimalinos, C.: The attenuation of solar UV radiation in lakes and the role of dissolved organic carbon, Limnol. Oceanogr., 40, 1381-1391, 1995.

Oh, N. H., Pellerin, B. A., Bachand, P. A. M., Hernes, P. J., Bachand, S. M., Ohara, N., Kavvas, M. L., Bergamaschi, B. A., and Horwath, W. R.: The role of irrigation runoff and winter rainfall on dissolved organic carbon loads in an agricultural watershed, Agricul. Ecosys. Environ., 179, 1-10, 2013.

Park, J.-H., Woo, B.-M., Kim, O.-R., Ahn, H.-C., and Kim, J.-S.: The effects of timber harvesting on soil chemical ingredients and stream water quality, Korean J. Ecol., 23, 9-15, 2000 (in Korean with English abstract).

Pellerin, B. A., Saraceno, J. F., Shanley, J. B., Sebestyen, S. D., Aiken, G. R., Wollheim, W. M., and Bergamaschi, B. A.: Taking the pulse of snowmelt: in situ sensors reveal seasonal, event and diurnal patterns of nitrate and dissolved organic matter variability in an upland forest stream, Biogeochemistry, 108, 183-198, 2012.

Perdue, E. M. and Ritchie, J. D.: Dissolved organic matter in freshwaters, in: Treatise on Geochemistry, edited by: Holland, H. D. and Turekian, K. K., Elsevier, Netherlands, 237-272, 2014.

Raymond, P. A. and Bauer, J. E.: Bacterial consumption of DOC during transport through a temperate estuary, Aq. Microb. Ecol., 22, 1-12, 2000. 
Raymond, P. A. and Saiers, J. E.: Event controlled DOC export from forested watersheds, Biogeochemistry, 100, 197-209, 2010.

Ryder, E., Jennings, E., de Eyto, E., Dillane, M., NicAonghusa, C., Pierson, D.C., Moore, K., Rouen, M., and Poole, R.: Temperature quenching of CDOM fluorescence sensors: temporal and spatial variability in the temperature response and a recommended temperature correction equation, Limnol. Oceanogr.-Methods, 10, 1004-1010, 2012.

Saraceno, J. F., Pellerin, B. A., Downing, B. D., Boss, E., Bachand, P. A. M., and Bergamaschi, B. A.: High-frequency in situ optical measurements during a storm event: Assessing relationships between dissolved organic matter, sediment concentrations, and hydrologic processes, J. Geophys. Res.-Biogeosci., 114, G00F09, doi:10.1029/2009JG000989, 2009.

Stedmon, C. A. and Markager, S.: Resolving the variability in dissolved organic matter fluorescence in a temperate estuary and its catchment using PARAFAC analysis, Limnol. Oceanogr., 50, 686-697, 2005.

Strohmeier, S., Knorr, K.-H., Reichert, M., Frei, S., Fleckenstein, J. H., Peiffer, S., and Matzner, E.: Concentrations and fluxes of dissolved organic carbon in runoff from a forested catchment: insights from high frequency measurements, Biogeosciences, 10, 905-916, doi:10.5194/bg-10-905-2013, 2013.
Waterloo, M. J., Oliveira, S. M., Drucker, D. P., Nobre, A. D., Cuartas, L. A., Hodnett, M. G., Langedijk, I., Jans, W. W. P., Tomasella, J., de Araujo, A. C., Pimentel, T. P., and Estrada, J. C. M.: Export of organic carbon in run-off from an Amazonian rainforest blackwater catchment, Hydrol. Process., 20, 2581-2597, 2006.

Watras, C. J., Hanson, P. C., Stacy, T. L., Morrison, M., Mather, J., Hu, Y. H., and Milewski, P.: A temperature compensation method for CDOM fluorescence sensors in freshwater, Limnol. Oceanogr.-Methods, 9, 296-301, 2011.

Weishaar, J. L., Aiken, G. R., Bergamaschi, B. A., Fram, M. S., Fujii, R., and Mopper, K.: Evaluation of specific ultraviolet absorbance as an indicator of the chemical composition and reactivity of dissolved organic carbon, Environ. Sci. Technol., 37, 47024708, 2003.

Wilson, H. F., Saiers, J. E., Raymond, P. A., and Sobczak, W. V.: Hydrologic drivers and seasonality of dissolved organic carbon concentration, nitrogen content, bioavailability, and export in a forested New England stream, Ecosystems, 16, 604-616, 2013.

Xie, Y. F.: Disinfection Byproducts in Drinking Water: Formation, Analysis, and Control, Lewis Pulbishers, Boca Raton, FL, 2004.

Yoon, B. and Raymond, P. A.: Dissolved organic matter export from a forested watershed during Hurricane Irene, Geophys. Res. Lett., 39, L18402, doi:10.1029/2012GL052785, 2012. 